\title{
Effects of lions on behaviour and endocrine stress in plains zebras
}

\author{
Stéphanie Périquet ${ }^{\mathrm{a}}$, Peter Richardson ${ }^{\mathrm{b}}$, Elissa Z. Cameron ${ }^{\mathrm{b}, \mathrm{d}, \mathrm{e}}$, André Ganswindt ${ }^{\mathrm{c}, \mathrm{d}}$, Lydia \\ Belton $^{\mathrm{d}}$, Elize Loubser ${ }^{\mathrm{d}}$, Fredrik Dalerum ${ }^{\mathrm{d}, \mathrm{f}, \mathrm{g}, \uparrow}$ \\ ${ }^{a}$ Department of Zoology and Entomology, University of the Free State, Qwaqwa Campus, Phuthaditjhaba, \\ South Africa \\ ${ }^{\mathrm{b}}$ School of Zoology, University of Tasmania, Hobart, Australia \\ ${ }^{c}$ Endocrine Research Laboratory, Department of Anatomy and Physiology, University of Pretoria, \\ Onderstepoort, South Africa \\ ${ }^{\mathrm{d}}$ Mammal Research Institute, Department of Zoology and Entomology, University of Pretoria, Pretoria, \\ South Africa \\ ${ }^{\mathrm{e}}$ School of Biological Sciences, University of Canterbury, Christchurch, New Zealand \\ ${ }^{\mathrm{f}}$ Research Unit of Biodiversity (UO-CSIC-PA), University of Oviedo, Mieres Campus, 33600 Mieres, Spain \\ ${ }^{\mathrm{g}}$ Department of Zoology, Stockholm University, 106 91, Stockholm, Sweden \\ $\uparrow$ Correspondence: F. Dalerum, Research Unit of Biodiversity (UMIB, UO-CSIC-PA), University of Oviedo, \\ Mieres, 33600 Mieres, Asturias, Spain. Email address: dalerumjohan@ uniovi.es; Phone: +34 985103000 \\ (Ext 5927)
}

Ethology 2017. 123: 667-674.

\begin{abstract}
Living under predation risk may alter both behaviour and physiology of potential prey. In extreme cases, such alterations may have serious demographic consequences, and recent studies support that non-lethal effects of predation may have broad ecological effects. However, behavioural and physiological responses to predation risk may be related to trade-offs associated with resource acquisition and direct predation risk. We validated an enzyme linked immuno-assay (EIA) for noninvasive monitoring of stress in plains zebras (Equus quagga) from faecal material. We used this assay in combination with behavioural data to assess if plains zebras living with and without lions (Panthera leo) in a mountain savannah in southern Africa differed in behaviour and physiology, and if such differences were influenced by seasons with contrasting resource availability. Zebra group sizes did not differ between areas with and without lions, but zebra groups had more juveniles in an area with lions than groups in an area without lions, but only during the wet season. Similarly, we observed differences in individual vigilance, foraging behaviour, and stress hormone concentrations, but all these differences were influenced by seasons. Despite these seasonal influences, our study did not suggest that zebras in an area with lions spent a higher proportion of time being vigilant, a lower proportion of time foraging, or had higher stress hormone levels. Our results instead suggest that zebras' responses to lion presence were highly context dependent and the result of complex interactions between resource abundance and cues about predation risk. Because of the obvious ecological and evolutionary ramifications of such findings, we argue that further research is needed to define the spatial and temporal scales over which predators impose indirect effects on their prey.
\end{abstract}

Key words: antipredator response, faecal glucocorticoid metabolites, validation, ACTH, foraging, stress, vigilance, predation risk, Equus quagga, Panthera leo 


\section{Introduction}

Potential prey often adopt behavioural responses to reduce the frequency of predator encounters or to decrease individual predation risk (Lima 1998). The non-lethal consequences of such behavioural adjustments, often termed risk effects, can have wide ramifications both on individual and population levels (Creel \& Christianson 2008), and may also have downstream cascade effects on ecosystem structures (Schmitz et al. 1997). Behavioural adjustments to predation risk may include shifts in habitat selection (Fischoff et al. 2007), decreased foraging efficiency (Barnier et al. 2014), adjustments of behavioural time budgets (Lima \& Bednekoff 1999; Périquet et al. 2012), and alterations in the level of gregarious behaviour (Thaker et al. 2010). Predation risk has generally been shown to cause increased group sizes in prey (Elgar 1989), which can be explained by a reduced individual predation risk in larger groups caused by dilution and confusion effects as well as increased collective vigilance (Hamilton 1971; Pulliam 1973; Lazarus 1979; Turner \& Pitcher 1986). However, living in large groups may also be linked to increased foraging competition (Dalerum et al. 2008), leading to a potential limitation in optimal group sizes. Predation risk can also constrain foraging through increased individual vigilance (Sinclair \& Arcese 1995; Périquet et al. 2010; Périquet et al. 2012), or by forcing animals to shift into less productive but safer habitats (Creel et al. 2005).

Predation risk may also have physiological consequences, partly related to an increased release of glucocorticoid stress hormones (Sheriff \& Thaler 2014). Although short term endocrine reactions to immediate predation risk may not carry broader physiological ramifications, chronic anticipatory stress may lead to a diverse array of pathologies, for instance reproductive failure and decreased immune function (Cizauskas et al. 2015, reviewed in Sapolsky 1992). Increased stress hormone levels as a response to predation risk have been observed in many populations (Clinchy et al. 2013), but recent arguments suggest that it may only be present if it is evolutionary beneficial (Boonstra 2013). The occurrence of chronic stress may also be highly context dependent (Sheriff et al. 2009). However, physiological stress responses to predation risk may have substantial demographic consequences for prey (Creel \& Christianson 2008), suggesting they may have broad ecological relevance (Hawlena \& Schmitz 2010).

Indirect effects of predation risk are not necessarily constant, either across time or space (Laundré et al. 2010). Prey often react differently to predators depending on temporal or spatial variation in local conditions (Caro 2005). Seasonal variation in temperature and precipitation can strongly modify habitat structure as well as forage quality and quantity (Blanchard \& Fritz 2008). Such temporal variation in available cover and food supply can influence indirect effects of predation by altering the relative costs and benefits of predator avoidance (Brown \& Kotler 2004). For instance, during seasons of low forage quality the cost of elevated levels of vigilance is more pronounced and there is a tendency of starved animals to take higher risks for foraging benefits (Lima \& Dill 1990). Therefore, it is informative to evaluate the indirect consequences of living under predation risk under seasons with contrasting levels of food supply, food quality and availability of cover.

In this study we evaluated how the presence of an apex predator, the African lion (Panthera leo), influenced group size, the number of juveniles, vigilance and foraging behaviour and glucocorticoid levels in the plains zebra (Equus quagga) during the wet and the dry seasons in northern South Africa. In addition, we provide a physiological validation for non-invasive stress monitoring in the plains zebra from faecal material using an enzyme linked immuno-assay (EIA). The plains zebra (zebra hereafter) is a non-territorial but social ungulate with a broad distribution across southern and eastern Africa. Zebras are specialized grazers and live in stable groups of 5-15 individuals, usually consisting of a stallion, up to six mares, and their offspring (Grubb 1981). They are not seasonal breeders in most of southern Africa (Skinner \& Chimimba 2005), including in our study region. Our study took place in a mountain savannah in South Africa, with substantial seasonal variation in 
precipitation and primary productivity (Mucina \& Rutherford 2006). We hypothesized that the presence of lions would influence gregarious behaviour, behavioural time budgets and physiological stress responses in zebras, and specifically evaluated if: 1) zebras living in the presence of lions would form larger social groups than zebras living in an area without lions, 2) zebra groups would contain less offspring in the presence of lions compared to groups living in an area without lions 3) zebras living in the presence of lions would spend a higher proportion of their time being vigilant and a lower proportion of time foraging than zebras living in an area without lions, 4) zebras living in the presence of lions would have higher vigilance scan rates than zebras living without lions, 5) zebras living in the presence of lions would have elevated glucocorticoid levels than zebras living without lions, and finally 6) the effects of predation risks would differ between periods of contrasting resource abundance, caused by altering trade-offs involving resource acquisition and predation risk.

\section{Materials and methods}

\section{Study Area}

We conducted the study in two private game reserves in the Waterberg region of Limpopo Province, South Africa; Lapalala Wilderness (Lapalala; $23^{\circ} 54^{\prime} 00^{\prime \prime} \mathrm{S}, 28^{\circ} 19^{\prime} 23^{\prime \prime}$ E) and Welgevonden Private Game Reserve (Welgevonden; 24 19’23” S, 2802’37” E). The two reserves are situated within $50 \mathrm{~km}$ of each other and are of similar size (Lapalala 36,000 ha; Welgevonden 37, $500 \mathrm{ha}$ ), topography, vegetation, and fauna (Dalerum \& Belton 2015). Topography consists of elevated plateaus and undulating rocky hills. The vegetation is classified as Waterberg moist mountain bushveld (Mucina \& Rutherford 2006), with relatively dense vegetation occurring at lower altitudes and more sparse woodlands prevailing at higher elevations (Isaacs et al. 2013). Both reserves are located within an area which experiences summer rainfall. Annual rainfall ranges from 650 to $900 \mathrm{~mm}$ with the majority of precipitation occurring from October to March. Average maximum summer temperature is $32^{\circ} \mathrm{C}$ whereas maximum winter temperature is $22^{\circ} \mathrm{C}$. Corresponding average minimum temperatures are $18^{\circ} \mathrm{C}$ during the summer and $4^{\circ} \mathrm{C}$ during the winter (Ben-Shahar 1987).

Both reserves are fenced and support over 50 species of mammals. The most common large herbivores are plains zebra, impala (Aepyceros melampus), blue wildebeest (Connochaetes taurinus) and warthog (Phacochoerus africanus) (Isaacs et al. 2013; Dalerum \& Belton 2015). Aerial censuses recorded 1019 zebras in Lapalala in 2007 and 656 zebras in Welgevonden in 2011. Elephants (Loxodonta africana) are present in Welgevonden but were absent in Lapalala at the time of the study. Lions went extinct in the region probably over 100 years ago but were introduced to Welgevonden in 1998 (Kilian 2003; Dalerum \& Belton 2015). They are still absent in Lapalala. During this study, the number of lions in Welgevonden ranged from 8 to 14 adults distributed across 2 prides and 1 coalition of males. These lions range across all of the reserve, so that there are no complete refugia from potential lion predation. Resident populations of other large predators in both reserves include leopards (Panthera pardus) and brown hyenas (Hyaena brunnea). Vagrant groups of African wild dogs (Lycaon pictus) and spotted hyenas (Crocuta crocuta) have been encountered in both reserves, but are not common. Cheetahs (Acinonyx jubatus) can be found at very low numbers in Welgevonden and are reported to be transitory in Lapalala. Although the zebras in Lapalala did not live in a predator free environment, they are not preferred prey for either leopards (Hayward et al. 2006) or brown hyaenas (Burgener \& Gusset 2003), and neither wild dogs nor spotted hyaenas occurred frequently enough to have imposed long-term effects on prey. Furthermore, zebras are one of the preferred prey for lions (Hayward \& Kerley 2005), including for the re-introduced lion population in Welgevonden (Kilian 2003). 


\section{Behavioural data collection}

We recorded group size and number of juveniles in a total of 43 groups of zebra in Lapalala and 51 in Welgevonden, and we conducted behavioural observation on 11 and 19 of these groups, respectively. None of the observed groups were bachelor herds or in mixed herds including other species. Behavioural observations were done on 49 individuals in Lapalala and on 77 individuals in Welgevonden. We only recorded behavioural data on foraging groups, i.e. groups in which at least half of the individuals were actively foraging (Dalerum \& Belton 2015). Behavioural observations were done between January 2009 and July 2012. For logistical reasons the observations were made mainly in open habitat, or in patches with good visibility in the woodlands. However, in both reserves they were spaced throughout the reserves and not focused in any particular location. Each individual was identified by its unique stripe patterns and therefore observed only once for each observation period. Although we did not have the zebra herds marked, we attempted to only collect data on each group once by sequentially moving between different areas of the reserves. Dry season observations were conducted from April to September (32 individuals in Lapalala and 46 in Welgevonden) and wet season observations between October and February (17 individuals in Lapalala and 31 in Welgevonden). We conducted observations from within a vehicle at distances ranging from 25-200 $\mathrm{m}$ to minimize disturbance. After animals had relaxed and resumed feeding with minimal signs of being disturbed, we recorded groups using a hand-held digital video camera for five minutes, or until the group had moved out of sight. We discarded the recording if the group was obviously disturbed by observer presence, indicated by repeated vigilance directed towards the vehicle. We recorded group size as the total number of adults and sub-adults as well as the number of juveniles present. We recorded the time budgets of adult individuals from the videos using focal sampling techniques. The behaviour of each individual was scored for five minutes or until the animal moved out of view. Minimum observation time for any animal included in the analyses was $2 \mathrm{~min}$, with an average focal duration of $4 \mathrm{~min}$ and $55 \mathrm{sec}(5 \mathrm{~min}$ for Lapalala and an average of 4 min and $52 \mathrm{sec}$ for Welgevonden). We scored an animal as vigilant when it had its feet stationary and its head raised above a horizontal position, scanning its surroundings. We scored an animal as foraging when it had its head lowered to the ground (i.e. cropping grass or searching for forage), irrespectively if it was moving or stationary. We scored an animal as moving if it took a minimum of three steps with its head raised above $90^{\circ}$ to the legs. In addition to recording time being vigilant (number of seconds spent being vigilance), we also summarized the number of times an animal was observed to scan its surroundings per observation period (i.e. vigilance scan rate - the number of times an animal was vigilant per unit of time). We attempted to separate social vigilance from vigilance targeting the surrounding environment, and only used the latter for the analyses. We scored social vigilance as any vigilance behaviour, defined as above, but clearly directed to one or several group members. Although we appreciate that some social vigilance may have been used to scan for predators, and vice versa, social vigilance can be substantial in African ungulates (e.g., Cameron \& du Toit 2005). We therefore believe that pooling vigilance types would have introduced larger errors in our data than the potential mis-identification of vigilance types with this observation protocol. We only used adult individuals for behavioural analyses, but we could not reliably record sex for the observed animals from the recordings. However, although we have not included sex in our behavioural analyses, the majority of the observed animals were females since breeding groups of zebras do not contain more than one adult male (Grubb 1981).

\section{Measurement of physiological stress}

We measured physiological stress non-invasively through determination of faecal glucocorticoid metabolite concentrations. When an adult animal was observed defecating, we collected a thoroughly mixed sample of approximately $5 \mathrm{ml}$ from the dropping within 15 minutes of deposition. We immediately stored samples on ice and subsequently at $-20{ }^{\circ} \mathrm{C}$ on return to the research base to reduce the risk of bacterial alteration of steroid composition post-defecation (Sheriff et al. 2011). Between June 2011 and July 2012 we collected 27 faecal samples from 24 different groups in 
Lapalala (15 samples during the dry and 12 samples during the wet season) and 28 faecal samples from 24 groups in Welgevonden (21 samples during the dry and 7 samples during the wet season). For each of the collected samples, we recorded the sex of the individual from which the sample came. We collected samples from 20 females and 7 males in Lapalala and from 19 females and 9 males in Welgevonden.

We lyophilised faecal samples until complete dryness, pulverised and passed them through a mesh strainer to separate the faecal powder from undigested faecal matter and fibrous material (Fieß et al. 1999). We then extracted $0.10-0.11 \mathrm{~g}$ of faecal powder by vortexing for 15 min with $80 \%$ ethanol in water $(3 \mathrm{ml})$. We centrifuged extracts at 1,500 $\mathrm{g}$ for $10 \mathrm{~min}$ and stored the supernatants at $-20{ }^{\circ} \mathrm{C}$ until assayed. We measured for immunoreactive faecal glucocorticoid metabolite concentrations in the extracts using an enzyme-immunoassay. The assay was using an antibody

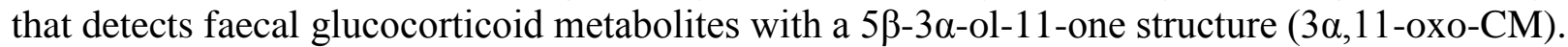
Details of the assay were first described by Möstl and Palme (2002). Serial dilutions of faecal extracts gave a displacement curve that was parallel to the respective standard curve (relative variation of the slope of respective trendlines $<5 \%$ ). Sensitivity of the assay at $90 \%$ binding was $3.0 \mathrm{ng} / \mathrm{g}$ dry faeces. Intra- and interassay coefficients of variation, determined by repeated measurements of high and low quality controls, ranged between $4.5-5.1 \%$ and $5.5-12.0 \%$, respectively. Faecal glucocorticoid metabolite concentrations were expressed as ng/g dry weight. Further details of the immunoassay, including cross-reactivities are described by Möstl and Palme (2002).

We evaluated the ability of the immunoassay to measure physiologically relevant glucocorticoid concentrations in plains zebra faeces through an adrenocorticotropic hormone (ACTH) challenge test, in combination with evaluating the physiological response to a temporary translocation (Fourie 2012). We immobilized two adult zebras (one stallion, 300kg and one mare, 200kg) in their original enclosure at the National Zoological Gardens of South Africa, Pretoria, with a combination of Etorphine (M99®, Novartis South Africa (Pty) LTD, South Africa) and Azaparone (Stressnil@, Janssen Pharmaceutica (Pty) LTD, South Africa). We translocated the animals to an adjacent veterinary hospital, where they were housed in separate outdoor enclosures for 14 days. A combination of Diprenorphine (M5050®, Novartis South Africa (Pty) LTD, South Africa) and Naltrexone (Naltrexone 50mg/ml, Kyron Laboratories (Pty) LTD, South Africa) and Naltrexone was administered intramuscularly to each animal to reverse the effects of the immobilization drugs. Individual faecal samples were collected during the day over the two-week study period, resulting in a total of 90 samples. Morning collections included samples that were voided overnight. After 9 days, we immobilized both zebras again and injected 1 IU/kg Synacthen ${ }^{\circledR}$ Depot (Novartis South Africa (Pty) LTD, South Africa) intramuscularly. We continued faecal sample collection for 5 days until the animals were transported back to their original enclosure. Median faecal glucocorticoid metabolite concentrations of samples collected from day one post-separation were used as hormone baseline level for each individual. Concentrations of faecal glucocorticoid metabolites increased continuously $24 \mathrm{~h}$ post-translocation, peaking at $80 \%$ (male) and $114 \%$ (female) above baseline after $96 \mathrm{~h}$ and $87 \mathrm{~h}$, respectively, and remained above baseline until ACTH administration. We observed a maximal increase in faecal glucocorticoid metabolite concentrations of $157 \%$ (male) and 133\% (female) above individual baselines 39 hours after ACTH injection (Figure S1). We argue that the substantial increase in faecal glucocorticoid metabolites concentrations demonstrated after translocation and in addition ACTH administration confirms that the immunoassay used detects biologically meaningful alterations in adrenocortical activity in the chosen hormone matrix of plains zebras (Sheriff et al. 2011). 


\section{Statistical Analysis}

We evaluated the effect of lion presence (i.e., reserve), season and their interaction on zebra group size using a generalized linear model with a Poisson error and a log link. We used a similar model to evaluate the effect of reserve, season and their interaction on the number of juveniles present in zebra groups. In this analysis, we used the number of juveniles as the response variable, and also added group size as a covariate. No overdispersion was detected in either of these models. We used generalized estimating equations to assess the effect of reserve, season and their interaction on proportion of time spent vigilant, proportion of time time spent foraging and vigilance scan rates (Zuur et al. 2009). In all these models, we added group size and number of juveniles as fixed effects, we used zebra group as a grouping variable and assumed an exchangeable correlation structure. We measured the proportion of time spent vigilant and proportion of time spent foraging as the ratio of the time (seconds) observed conducting each behaviour to the total observation time, an added these proportions in response variables in two models fitted with a binomial error structure and a logit link. We fitted the model on vigilance scan rates on raw frequencies, but we added the time each animal was observed as an offset to ensure that the data were treated as rates in the model (i.e. our parameters were effectively fitted on scans per unit of time, Crawley 2013). This model was fitted with a Poisson error and a log link. Finally, we used linear mixed effect models to assess the effect of reserve, season and their interaction on faecal glucocorticoid metabolite concentrations. Concentrations were log transformed to account for heteroschedasticity. We also included group size, number of juveniles and sex as fixed effects and added group as a random factor. For all models, we evaluated fixed effects using sequential likelihood ratio tests, which is appropriate for these types of models (Zuur et al. 2009). For significant interaction terms, we contrasted the reserves within each season by using post-hoc contrasts on least-square means (Lenth 2016), with the alpha levels adjusted for multiple comparisons by controlling for the false discovery rate (Benjamini \& Hochberg 1995). We used this specific contrast since it is directly relevant for our evaluation of the effects of predation risk on behaviour and physiology. We conducted statistical analysis in R version 3.2.2 (http://www.r-project.org) using the packages 'geepack' (Højsgaard et al. 2006), 'Ismeans' (Lenth 2016), and 'nlme' (Pinheiro et al. 2016).

\section{Results}

\section{Group size and number of juveniles}

Neither the presence of lions $\left(\chi^{2}=0.54, \mathrm{df}=1, \mathrm{p}=0.46\right)$, season $\left(\chi^{2}=2.28, \mathrm{df}=1 \mathrm{p}=0.13\right)$ nor the interaction between presence of lions and season $\left(\chi^{2}=0.38, \mathrm{df}=1, \mathrm{p}=0.54\right)$ significantly affected zebra group size. Group sizes in the presence of lions ranged from 3 to 17 (5.9 \pm 2.3 , mean $\pm \mathrm{sd})$ and in the absence of lions from 2 to $12(5.5 \pm 2.6)$. However, the interaction between presence of lions and season had a significant effect on the number of juveniles $\left(\chi^{2}=5.8, \mathrm{df}=1, \mathrm{p}=0.02\right)$. While there was no effect of lion presence during the dry season (Welgevonden 1.4 \pm 1.0 ; Lapalala $\left.0.95 \pm 1.0 ; \beta=-0.33, z=-1.14, p_{a d j}=0.25\right)$, the number of juveniles showed a tendency to be higher in the absence than in the presence of lions during the wet season (Welgevonden $0.62 \pm 0.92$; Lapalala $\left.1.2 \pm 0.88 ; \beta=0.70, \mathrm{z}=2.08, \mathrm{p}_{\mathrm{adj}}=0.07\right)$. Group size also had a positive effect on the number juveniles $(\beta=0.09, \mathrm{z}=2.93, \mathrm{p}=0.02)$.

\section{Vigilance and foraging behaviour}

The interaction between the presence of lions and season had significant effects on proportion of time spent vigilant $\left(\chi^{2}=7.15, \mathrm{df}=1, \mathrm{p}<0.01\right)$, proportion of time spent foraging $\left(\chi^{2}=10.3, \mathrm{df}=1\right.$, $\mathrm{p}<0.01)$ and vigilance scan rates $\left(\chi^{2}=4.8, \mathrm{df}=1, \mathrm{p}=0.03\right)$. Zebras spent less proportion of time being vigilant in the presence of lions compared to zebras in the absence of lions during the wet ( $\beta$ $\left.=-1.23, \mathrm{z}=-2.80, \mathrm{p}_{\mathrm{adj}}=0.02\right)$ but not during the dry season $\left(\beta=1.45, \mathrm{z}=1.06, \mathrm{p}_{\mathrm{adj}}=0.15\right.$; Fig. 1a). Contrarily, zebras in the presence of lions spent a higher proportion of time foraging than zebras in the absence of lions during the wet season $\left(\beta=1.20, z=2.36, p_{\text {adj }}=0.02\right)$ but less during the dry season $\left(\beta=-1.64, z=-2.21 p_{a d j}=0.02\right.$; Fig. $\left.1 b\right)$. Similarly, there was a trend for zebras in the 

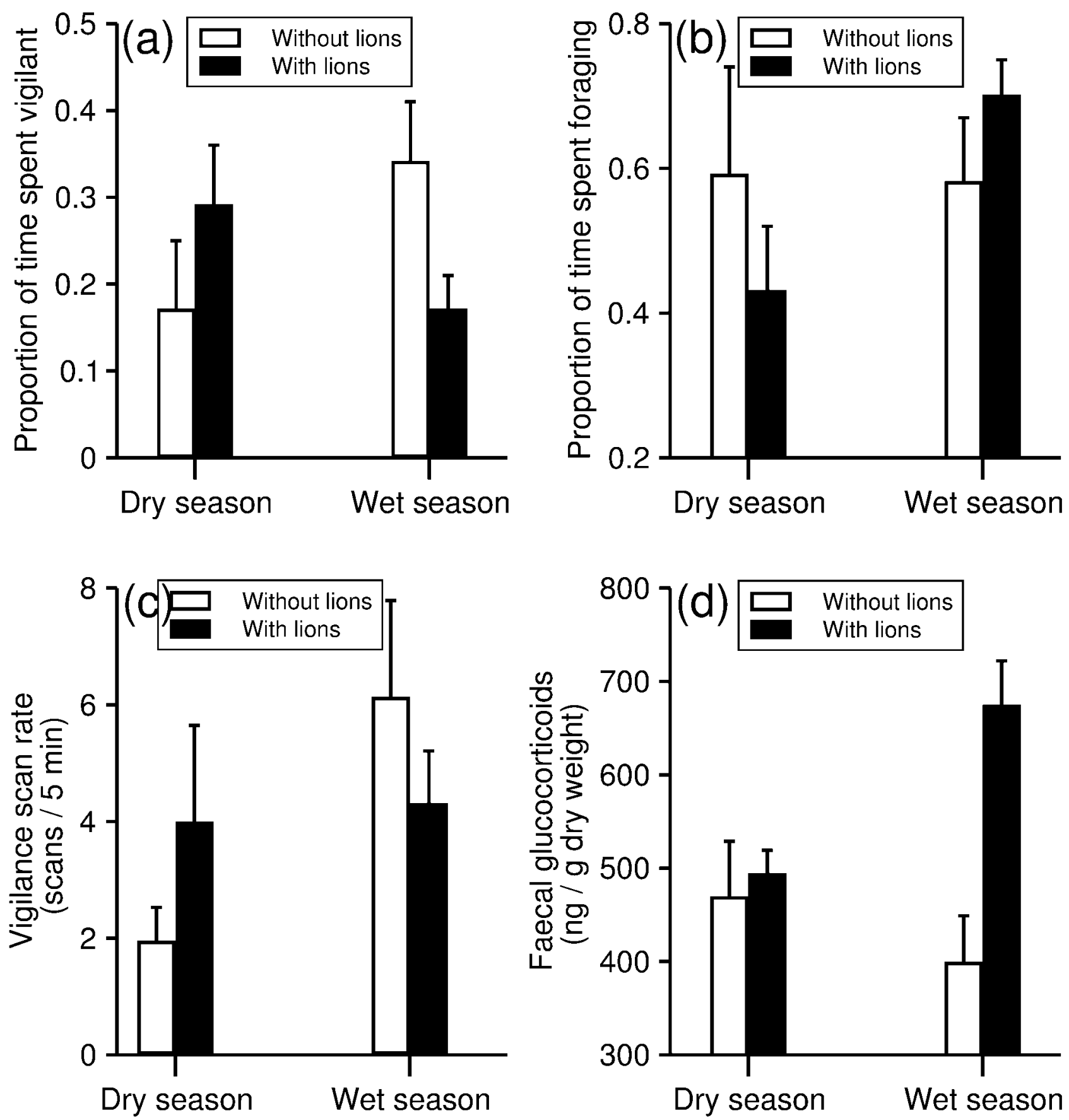

Figure 1: Proportion of time spent vigilant (a), proportion of time spent foraging (b), vigilance scan rates (scans / 5 min observation period) (c), and faecal glucocorticoid metabolite concentrations (d) in zebras living without (Lapalalala) and with lions (Welgevonden) during the dry and wet season. Figure presents mean \pm SE of group means.

presence of lions to have lower vigilance scan rates than in the absence of lions during the wet season $\left(\beta=-0.81, \mathrm{z}=-1.56, \mathrm{p}_{\mathrm{adj}}=0.12\right)$, and a reversed pattern for the dry season $(\beta=0.43, \mathrm{z}=$ $1.892, p_{\text {adj }}=0.11$, Fig. 1c). Neither group size nor number of juveniles affected the proportion of time zebras spent vigilant (group size: $\chi^{2}=3.78$, $\mathrm{df}=1, \mathrm{p}=0.05$; number of juveniles: $\chi^{2}=1.83$, df $=1, \mathrm{p}=0.18$ ), the proportion of time spent foraging (group size: $\chi^{2}=1.11, \mathrm{df}=1, \mathrm{p}=0.29$; number of juveniles: $\chi^{2}=0.28, \mathrm{df}=1, \mathrm{p}=0.60$ ), or vigilance scan rates (group size: $\chi^{2}=0.87, \mathrm{df}=1, \mathrm{p}=$ 0.35 ; number of juveniles: $\chi^{2}=0.26, \mathrm{df}=1, \mathrm{p}=0.61$ ). 


\section{Stress hormone levels}

The interaction between presence of lions and season had a significant effect on faecal glucocorticoid metabolite concentrations $\left(\chi^{2}=5.3, \mathrm{df}=1, \mathrm{p}=0.02\right)$. There was a trend for faecal glucocorticoid metabolite concentrations to be higher in the presence than in the absence of lions during the wet season $\left(\beta=-0.37, \mathrm{z}=-2.1, \mathrm{p}_{\mathrm{adj}}=0.09\right)$ but not during the dry season $(\beta=0.15, \mathrm{z}=$ $1.13, \mathrm{p}_{\mathrm{adj}}=0.26$; Fig. 1d). Concentrations of faecal glucocorticoid metabolites were not affected by group size $\left(\chi^{2}=0.00, \mathrm{df}=1, \mathrm{p}=0.95\right)$, number of juveniles $\left(\chi^{2}=0.37, \mathrm{df}=1, \mathrm{p}=0.54\right)$ or $\operatorname{sex}\left(\chi^{2}=\right.$ $0.19, \mathrm{df}=1, \mathrm{p}=0.66)$.

\section{Discussion}

Although we found significant interaction effects between the presence of lions and season on several aspects of zebra behaviour and stress physiology, our study did not indicate that the presence of lions uniformly caused increased vigilance, decreased foraging time, or increased stress hormone levels in the observed zebra populations. These results contradict accumulated evidence of indirect effects of predation risk (Preisser et al. 2005), but agree with recent suggestions that such effects may not always present (Middleton et al. 2013, although see Creel et al. 2015 for an opposing view). We suggest two potential explanations for these apparent discrepancies. First, both experimental (Schmitz 2007) and meta-data based studies (Preisser et al. 2005; Preisser et al. 2009) have highlighted that the anti-predatory responses of prey are highly context dependent. In particular, predator hunting mode (Schmitz 2008), resource availability (Bolnick \& Preisser 2005), expected encounter rate (Courbin et al. 2016) and life history characteristics (Boonstra 2013) have been suggested to alter how prey respond to predator presence and predation risk. These factors are also likely to interact in complex ways (Preisser et al. 2009; Creel et al. 2014). Therefore, we could expect both large inter- and intra-population variation in the relative demographic consequences of direct and indirect predation effects. Second, because of the dramatic consequences of failing to detect predation, anti-predatory behaviour is under strong selection pressure (Blumstein et al. 2004). Therefore, anti-predatory behaviour may persist in prey populations that have lost past predators, if the evolutionary costs are relatively low (Le Saout et al. 2015). We suggest that a combination of these two factors, i.e. highly context dependent responses to lion presence in Welgevonden and latent anti-predatory behaviour in the now lion free Lapalala could have caused the observed results in this study. Such an interpretation would highlight that the presence of apex predators alone may not necessarily impose stronger ecosystem effects that those caused by additive prey mortality caused by predation.

We suggest that complex interactions between resource abundance, available vegetation cover and predator exposure may have caused the observed seasonal influences on the effects of lion presence on zebra vigilance and foraging behaviours and physiology. Such interactions have previously been implied for zebras (Fischoff et al. 2007; Thaker et al. 2010; Barnier et al. 2014). Although there were seasonal influences on the differences between the two reserves in terms of zebra behaviour and physiology, we did not find a stronger effect of lion presence on all aspects of behaviour and physiology. Instead, during the wet season we found that animals spent more time vigilant and less time foraging in the lion free environment of Lapalala. In addition, the trend for physiological stress to have been higher in the presence than in the absence of lions was only suggested for the wet season. These results contradict our intuition that any additional stressor such as predation risk would have more severe consequences during periods with limited resources (e.g, Brown 1988), and highlight that the interplay between predation risk, prey dynamics and resource dynamics can interact in surprising ways (Preisser et al. 2009). We note here that such interactions may not always result in negative net effects of predation risk on prey behaviour and physiology, at least not uniformly across a landscape. 
Similarly, the presence of lions did not seem to have caused any major effects on zebra group sizes. This result contradicts previous observations which have shown a positive association between predation risk and zebra group sizes (Thaker 2010; Schmitt 2014). Both social and environmental factors may constrain optimal group size in addition to effects of predation risk. For instance, feral horse (Equus caballus) mares not associated with breeding groups are in poorer body condition and have lower reproductive success compared to group living ones (Linklater et al. 1999), and social bonds enhance mare reproductive success (Cameron et al. 2009). We find it likely that similar social mechanisms may have affected zebra group sizes independent of predation risk. Increased group sizes may also carry costs in terms of overly complex social relations or increased foraging competition (Trivers 1985). While group sizes in gregarious species with less strong social bonds may be directly caused by interactions between foraging competition and predation risk, our data suggest that zebra group sizes may be caused by interactions between resource competition, predation risk and social constraints on gregarious behaviour.

Our results indicate that zebras modified the duration of their vigilance scans more than vigilance scan rates, and that zebras living without lions spent a higher proportion of time being vigilant than zebras living with lions, but only during the wet season. This relationship was accompanied by a reversed pattern in proportion of time spent foraging. We suggest that these results point to a limited effect of chronic predation risk on individual vigilance. Instead, variation in food supply may have regulated individual time budgets (Dalerum et al. 2008). However, we point out that any lack of effect of lion presence on individual vigilance could also partly have been caused by a switch between vigilance types. Vigilance can either be of low intensity and carried out while simultaneously conducting other behaviour behaviour, or as intense vigilance where the individual does nothing else but scan its surroundings (Blanchard and Fritz 2007). In the present study, both types of vigilance were pooled together, so that any adjustments between different types of vigilance would have gone unnoticed. Hence, we suggest that vigilance probably at least to some extent was unrelated to predation risk, and that any direct possible effects of predation risks were manifested in shifts between different types of vigilance rather than in adjusting individual time budgets.

Although our data suggest limited effects of lion presence on several aspects of zebra behaviour and endocrine physiology, we provide some caveats to our study. First, we have an effective sample size of one. Although this is an obvious statistical limitation (e.g., Hurlbert 1984), we still argue that our observations are informative. However, we urge for caution in generalizing these results to other geographic areas and ecological situations. Second, despite our attempts to not record social vigilance we could easily have mistaken different vigilance targets in our observations. However, if social vigilance caused the observed results, lion-induced vigilance in Welgevonden would have had to be traded for social vigilance in the lion free Lapalala. We find such an explanation unlikely. Second, prey density has been observed to influence how prey responds to predation risk (Guariento et al. 2015). In our study, there was lower zebra density in the reserve containing lions that in the reserve that did not. We can not rule out that some of our results could have been caused by these differences in zebra densities, and that density dependent processes could have off-set any potential difference in behaviour and physiology caused by the presence of lions in Welgevonden. Third, we have quantified time budgets of foraging groups (i.e. animals that were actively foraging), but not measured total time budgets. Hence, we could not with our sample protocol evaluate if there were large scale temporal shifts in how these zebras allocated their time. Such shifts could potentially off-set short term behavioural alterations. We argue that studies quantifying total time budgets and activity patterns (e.g., across 24 hour periods) would be highly informative for our understanding of how prey respond to altering predation risks. Finally, although Lapalala was free of lions, it was not a predator free environment (Dalerum \& Belton 2015). Because prey may exhibit drastically different responses to predation risk from predators with different hunting modes (Schmitz 2008), 
exposure to other carnivores such as leopards and brown hyaenas, may have altered the behavioural and physiological comparisons in unexpected ways.

To conclude, our results contradicted that the presence of a large apex predator, the African lion, necessarily will cause increased vigilance, decreased foraging and increased stress hormone levels in one of its preferred prey species. Instead, our results suggested that the effects of lion presence on zebras were highly context dependent, and the result of complex interactions between resource abundance and cues of predation risk. We further suggest that time required for foraging may have driven individual time budgets more than the predation induced need to be vigilant, and that any predator induced effects of vigilance may have been manifested in shifts in types of vigilance rather than in adjusting proportion of time being vigilant. Since the presence of apex predators may not uniformly cause strong shifts in prey behaviour, and we argue that further research is needed to define the spatial and temporal scales of which predators impose indirect effects on their prey.

\section{Acknowledgements}

We are grateful to managers and staff at Lapalala Wilderness and Welgevonden Game Reserve for permission to carry out the research and for logistic support. Adrian Tordiffe of the National Zoological Gardens in Pretoria kindly assisted with the ACTH validation experiment. This work was supported by the National Geographic/Wait's Foundation (grant number W32-08), the National Research Foundation in South Africa (grant numbers SFP2008072900003 and IFR2011032400087), the Ministry of Economy and Competitiveness in Spain (grant number RYC2013-14662), University of the Free State, University of Pretoria and University of Tasmania. We undertook fieldwork following the requirements by the University of Tasmania Animal Ethics Committee (Permit number A12432) and the Animal Use and Care Committee of University of Pretoria (AUCC, Reference EC17-12). We performed ACTH validation experiment with approval of the University of Pretoria AUCC (Reference EC058-11) and the Ethics and Scientific Committee of the National Zoological Gardens of South Africa (Reference P11/10).

\section{References}

Barnier, F., Valeix, M., Duncan, P., Chamaillé-Jammes, S., Barre, P., Loveridge, A. J., Macdonald, D. W. \& Fritz, H. 2014: Diet quality in a wild grazer declines under the threat of an ambush predator. Proc. Roy. Soc. B 281, 20140446.

Benjamini, Y., \& Hochberg, Y. 1995: Controlling the false discovery rate: a practical and powerful approach to multiple hypothesis testing. J Roy. Stat. Soc. B, 57, 289-300.

Ben-Shahar, R. 1987: Grasses and habitat relationships on a sour bushveld nature reserve. Vegetation 72, 45-49.

Blanchard, P., \& Fritz, H. 2007: Induced or routine vigilance while foraging. Oikos 116, 16031608.

Blumstein, D. T., Daniel, J. C., \& Springett, B. P. 2004: A test of the multi-predator hypothesis: rapid loss of antipredator behavior after 130 years of isolation. Ethology 110, 919—934.

Bolnick, D. I., \& Preisser, E. L. 2005: Resource competition modifies the strength of trait-mediated predator-prey interactions: a meta-analysis. Ecology 86, 2771-2779.

Boonstra, R. 2013: Reality as the leading cause of stress: rethinking the impact of chronic stress in nature. Funct. Ecol. 27, 11-23.

Brown, J. S. 1988: Patch use as an indicator of habitat preference, predation risk, and competition. Behav. Ecol. Soc. 22, 37-47.

Brown, J. S., \& Kotler, B. P. 2004: Hazardous duty pay and the foraging cost of predation. Ecol. Lett. 7, 999-1014.

Burgener, N., \& Gusset, M. 2003: The feeding habits of brown hyaenas (Hyaena brunnea) on a game ranch in Limpopo Province, South Africa. Afr. Zool. 38, 181-184. 
Cameron, E. Z. \& du Toit, J. T. 2005: Social influences on vigilance behaviour in giraffes, Giraffa camelopardalis. Anim. Behav. 69, 1337-1344.

Cameron, E. Z., Setsaas, T. H., \& Linklater, W. L. 2009: Social bonds between unrelated females increase reproductive success in feral horses. Proc. Nat. Acad. Sci. 106, 13850-13853.

Caro, T. M. 2005: Antipredator defenses in birds and mammals. University of Chicago Press, Chicago.

Cizauskas, C. A., Turner, W. C., Pitts, N. \& Getz, W. M. 2015: Seasonal patterns of hormones, macroparasites, and microparasites in wild African ungulates: the interplay among stress, reproduction, and disease. PLoS ONE 10, e00120800.

Clinchy, M., Sheriff, M. J. \& Zanette, L. Y. 2013: Predator-induced stress and the ecology of fear. Funct. Ecol. 27, 56-65.

Courbin, N., Loveridge, A. J., Macdonald, D. W., Fritz, H., Valeix, M., Makuwe, E. T., \& Chamaille-Jammes, S. 2016: Reactive responses of zebras to lion encounters shape their predator-prey space game at large scale. Oikos 125, 829-838.

Crawley, M. J. 2013: The R book, second edition. John Wiley \& Sons Ltd, Chichester, UK.

Creel, S., \& Christianson, D. 2008: Relationships between direct predation and risk effects. Tr. Ecol. Evol. 23, 194-201.

Creel, S., Schuette, P., \& Christianson, D. 2014: Effects of predation risk on group size, vigilance, and foraging behavior in an African ungulate community. Behav. Ecol. 24, 773-784.

Creel, S., Winnie, J., \& Christianson, D. 2015: Underestimating the frequency, strength and cost of antipredator responses with data from GPS collars: an example with wolves and elk. Ecol. Evol. 16, 5189-5200.

Creel, S., Winnie, J. A., Maxwell, B., Hamlin, K., \& Creel, N. M. 2005: Elk alter habitat selection as an antipredator response to wolves. Ecology 86, 3387-3397.

Dalerum, F., \& Belton, L. 2015: African ungulates recognize a locally extinct native predator. Behav. Ecol. 26, 215-222.

Dalerum, F., Lange, H., Skarpe, C., Rooke, T., Inga, B. H., \& Bateman, P. W. 2008: Foraging competition, vigilance and group size in two species of gregarious antelope. S. Afr. J. Wildl. Res. 38, 138-145.

Elgar, M. A. 1989: Predator vigilance and group size in mammals and birds: a critical review of the empirical evidence. Biol. Rev. 64, 13-33.

Fischoff, I. R., Sundaresan, S. R., Cordingley, J. \& Rubenstein, D. 2007: Habitat use and movements of plains zebra (Equus burchelli) in response to predation danger from lions. Behav. Ecol. 18, 725-729.

Fourie, C. E. 2012: Vigilance behaviour and its endocrine correlates in Plains zebra (Equus burchelli) living in a predator-free landscape. M.Sc. thesis. University of Pretoria, Pretoria.

Guariento, R. D., Carneiro, L. S., Esteves, F. A., Jorge, J. S., \& Caliman, A. 2015: Conspecific density affects predator-induced prey phenotypic plasticity. Ecosphere 6, 106

Grubb, P. 1981: Equus burchelli. Mamm. Spec. 157, 1-9.

Hamilton, W. D. 1971: Geometry for the selfish herd. J. Theor. Biol. 31, 295-311.

Hawlena, D., \& Schmitz, O. J. 2010: Physiological stress as a fundamental mechanism linking predation to ecosystem functioning. Am. Nat. 176, 537-556.

Hayward, M. W., Henschel, P., O'Brien, J., Hofmeyr, M., Balme, G., \& Kerley, G. I. H. (2006: Prey preferences of the lopard (Panthera pardus). J. Zool. 270, 298-313.

Hayward, M. W., \& Kerley, G. I. H. 2005: Prey preferences of the lion (Panthera leo). J. Zool. 267, 309-322.

Hurlbert, S. H. 1984: Pseudoreplication and the design of ecological field experiments. Ecol. Monogr. 54, 187-211.

Højsgaard, S., Halekoh, U., \& Yan, J. 2006: R package geepack for Generalized Estimating Equations. J. Stat. Softw. 15, 1-11.

Isaacs, L., Somers, M. J., \& Dalerum, F. 2013: Effects of prescribed burning and mechanical bush clearing on ungulate space use in an African savannah. Rest. Ecol. 21, 260-266. 
Kilian, P. J. 2003: The ecology of reintroduced lions on the Welgevonden Private Game Reserve. M. Sc. thesis. University of Pretoria, Pretoria.

Laundré, J. W., Hernández, L. \& Ripple, W. J. 2010: The landscape of fear: the ecological implications of being afraid. Open Ecol. J. 3, 1-7.

Lazarus, J. 1979: The early warning function of flocking in birds: an experimental study with captive quelea. Anim. Behav. 27, 855-865.

Lenth, R. V. 2016: Least-Squares means: The R package lsmeans. J. Stat. Softw. 69, 1-33.

Le Saout, S., Martin, J. L., Blanchard, P., Cebe, N., Hewison, A. J. M., Rames, J. L., \& ChamailléJammes, S. 2015: Seeing a ghost? Vigilance and its drivers in a predator-free world. Ethology 121, 651-660.

Lima, S. L. 1998: Nonlethal effects in the ecology of predator-prey interactions. Bioscience 48, 2534.

Lima, S. L., \& Bednekoff, P. A. 1999: Temporal variation in danger drives antipredator behavior: the predation risk allocation hypothesis. Am. Nat. 153, 649-659.

Lima, S. L., \& Dill L., 1990: Behavioral decisions made under the risk of predation: a review and prospectus. Can. J. Zool. 68, 619-640.

Linklater, W. L., Cameron, E. Z., Minot, E. O., \& Stafford, K. J. 1999: Stallion harassment and the mating system of horses. Anim. Behav. 58, 295-306.

Middleton, A. D., Kauffman, M. J., McWhirther, E. J., Jimenez, M. J., Cook, R. C., Cook, J. G., Albeke, S. E., Sawyer, H., \& White, P. J. 2013: Linking anti-predator behaviour to prey demography reveals limited risk effects of an actively hunting large carnivore. Ecol. Lett. 16, 1023-1030.

Möstl, E., \& Palme, R. 2002: Hormones as indicators of stress. Dom. Anim. Endocr. 23, 67-74.

Mucina, L., \& Rutherford, M. C. 2006: The vegetation of South Africa, Lesotho and Swaziland. Streliza 19. South African National Biodiversity Institute, Pretoria.

Périquet, S., Todd-Jones, L., Valeix, M., Stapelkamp, B., Elliot, N., Wijers, M., Pays, O., Fortin, D., Madzikanda, H., Fritz, H., Macdonald, D. W. \& Loveridge, A. J. 2012: Influence of immediate predation risk by lions on the vigilance of prey of different body size. Behav. Ecol. 23, 970-976.

Périquet, S., Valeix, M., Loveridge, A. J., Madzikanda, H., Macdonald, D. W. \& Fritz, H. 2010: Individual vigilance of African herbivores while drinking: the role of immediate predation risk and context. Anim. Behav. 79, 655-671.

Pinheiro, J., Bates, D., DebRoy, S., Sarkar, D. \& R Core Team 2016: nlme: Linear and nonlinear mixed effects models. R package version 3.1-124. http://CRAN.R-project.org/package=nlme.

Pulliam, R. H. 1973: On the advantages of flocking. J. Theor. Biol. 38, 419-422.

Preisser, E. L., Bolnick, D. I., \& Benard, M. F. 2005: Scared to death? The effects of intimidation and consumption in predator-prey interactions. Ecology 86, 501-509.

Preisser, E. L., Bolnick, D. I., \& Grabowski, J. H. 2009: Resource dynamics influence the strength of non-consumptive predator effects on prey. Ecol. Lett. 12, 315-323.

Sapolsky, R. M. 1992: Neuroendocrinology of the stress response. In: Behavioral Endocrinology (Becker, J. B., Breedlove, S. B. \& Crews, D., eds.). MIT Press, Cambridge, Massachusetts. pp. 287-324.

Schmitz, O. J. 2007: Predator diversity and trophic interactions. Ecology 88, 2415-2426.

Schmitz, O. J. 2008: Effects of predator hunting mode on grassland ecosystem function. Science 319, 952-964.

Schmitz, O. J., Beckerman, A. P., \& O`Brien, K. M. 1997. Behaviorally mediated trophic cascades: Effects of predation risk on food web interactions. Ecology 78, 1388-1399.

Schmitt, M. A., Stears, K., Wilmers, C. C., \& Shrader, A. M. 2014: Determining the relative importance of dilution and detection for zebra foraging in mixed-species herds. Anim. Behav. 96, 151-158.

Sheriff, M., Dantzer, B., Delehanty, B., Palme, R., \& Boonstra, R. 2011: Measuring stress in wildlife: techniques for quantifying glucocorticoids. Oecologia 166, 869-887. 
Sheriff, M., Krebs, C. \& Boonstra, R. 2009: The sensitive hare: sublethal effects of predator stress on reproduction in snowshoe hares. J. Anim. Ecol. 78, 1249-1258.

Sheriff, M. \& Thaler, J. S. 2014: Ecophysiological effects of predation risk; an integration across disciplines. Oecologia 176, 607-611.

Sinclair, A. R., \& Arcese, P. 1995: Population consequences of predation-sensitive foraging: the Serengeti wildebeest. Ecology 76, 882-891.

Skinner, J., \& Chimimba, C. 2005: Mammals of the southern African subregion. Cambridge University Press, Cambridge.

Thaker, M., Vanak, A. T., Owen, C. R., Ogden, M. B. \& Slotow, R. 2010: Group dynamics of zebra and wildebeest in a woodland savanna: effects of predation risk and habitat density. PLoS ONE 5, e12758.

Trivers, R. L. 1985: Social evolution. Benjamin Cummins, Menlo Park.

Turner, G. F., Pitcher, T. J. 1986: Attack abatement: a model for group protection by combined avoidance and dilution. Am. Nat. 128, 228-240.

Zuur, A. F., Ieno, E. N., Walker, N., Saveliev, A. A., \& Smith, G. M. 2009: Mixed effects models and extensions in ecology with R. Springer, New York. 

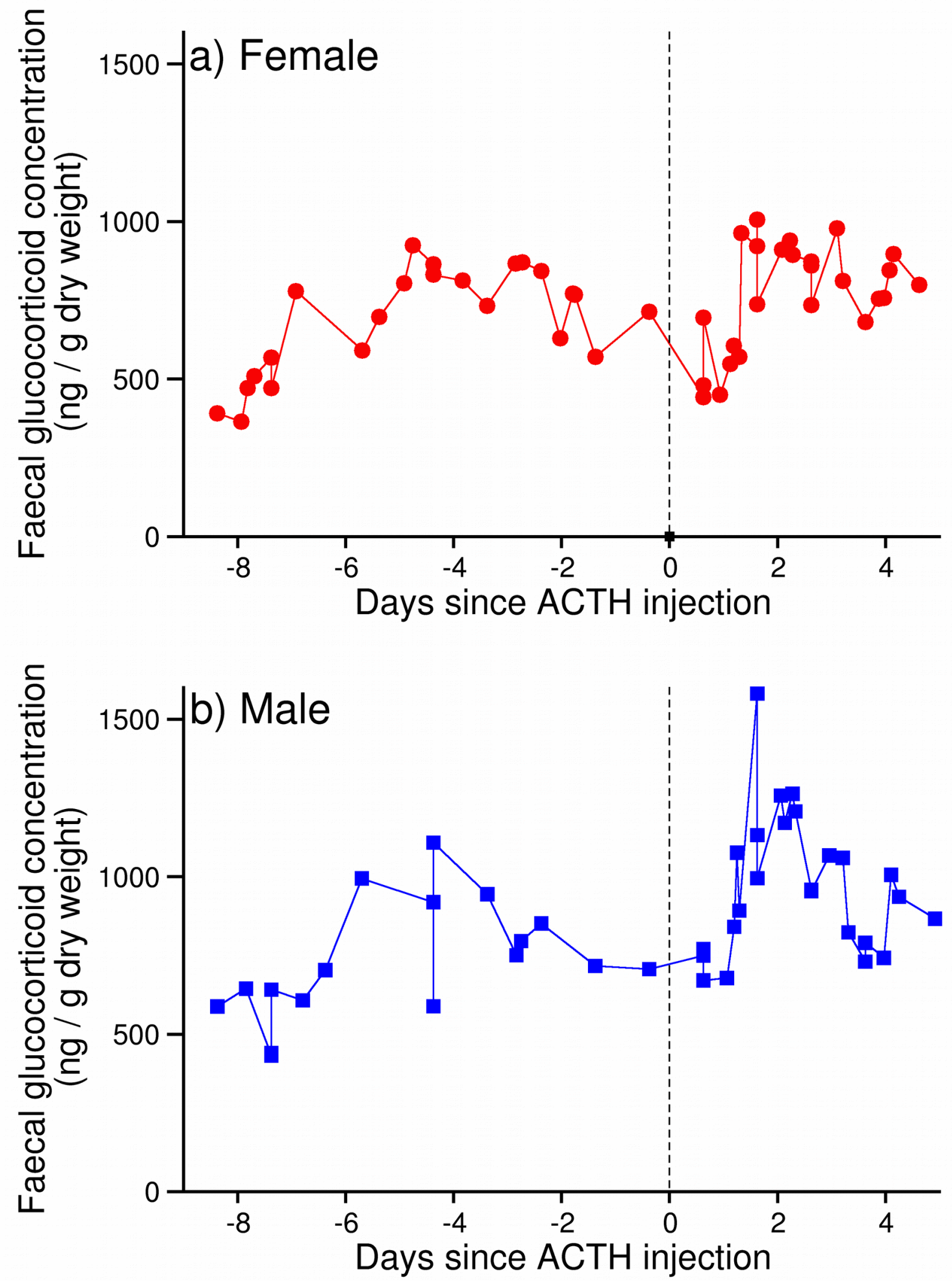

Figure S1. Endocrine profiles of faecal clucocorticoid metabolites in one female (a) and one male (b) zebra prior to and after the incetion with endogenuous adrenocorticotrophic hormone (ACTH). 